\title{
Study on Promoting Significance of Big Data Analysis for E-commerce Marketing
}

\author{
Xiaoming Lou \\ Jinhua Polylechnic, Jinhua Zhejiang, 321017, China
}

Keywords: Big data, E-commerce marketing, Promoting significance, Study.

\begin{abstract}
This paper first summarizes big data and marketing briefly, analyzes e-commerce marketing mode based on big data and finally summarizes the promoting significance of big data analysis for e-commerce marketing. It expects to promote the improvement of marketing ability and comprehensive competitiveness of Chinese e-commerce enterprises.
\end{abstract}

\section{Introduction}

In recent years, the comprehensive development of 4G technology, cloud computing and internet technology has greatly changed the work and life pattern of people. Under such circumstances, traditional consumption habits of people have also changed and network consumption has become more and more. This provides development opportunities for efficient marketing work of e-commerce enterprises. E-commerce enterprises must fully apply big data analysis technology for comprehensive analysis on purchasing habits, demands and social relation of consumers, realize website SEO optimization, implement member marketing and make media advertisement pertinently on this basis improve product quality and performance constantly and create more economic benefits on the basis of providing consumers with shopping experience of higher quality.

\section{Overview on big data and marketing}

\section{Meaning and influence of big data}

Big data refer to the realization of real-time collection of information and data by various means. It is required to fully apply relevant platforms and websites etc. in the process. Data and information collected can produce more economic benefits for enterprises. Currently, big data analysis has been widely applied in each field and the government has improved service quality greatly in the process of applying big data. Enterprises can record information including consumption habits and features comprehensively through big data analysis. This shows that comprehensive utilization of data by enterprises can not only provide basis for internal management and production, but also be good for providing high-quality services for consumers. Therefore, it has important significance for the realization of sustainable development by enterprises. In the forward position in commercial field, big data analysis must be fully applied in e-commerce development. Meanwhile, marketing adjustment should be made pertinently so as to grasp development opportunities of the era.

\section{Marketing}

Marketing master Philip Kotler put forward in 2005 that enterprises must specify marketing communication means, establish marketing plan and specific measures for action based on the result of marketing communication and pay high attention to direct marketing communication investment in the operational process. China has developed multiple representative systems in the process of studying marketing theory and pointed out that marketing must be oriented reasonably and personalized features of customer communication service system must be improved so as to reduce operating costs of enterprises. First, accurate market positioning is the key during the improvement of marketing level. Market is the basis for the implementation of marketing work by enterprises as well 
as the premise of economic profit creation by enterprises. Second, individuation level of services should be improved. Third, costs should be reduced and more returns will be created.

\section{E-commerce marketing mode based on big data}

To improve comprehensive competitiveness in the operational process under the times background of big data, e-commerce enterprises must update their management ideas, integrate big data closely in marketing and establish a brand-new e-commerce marketing mode so as to meet development demands of the era. E-commerce enterprises should analyze big data in detail in the operational process so as to improve the pertinence and personalized features of services and guarantee the improvement of efficiency of marketing mode. Moreover, they can also realize the development of brand-new services and products and reduce capital investment constantly in their business process so as to create more economic benefits and lay a good foundation in the process of full application of big data.

\section{Website SEO optimization based on big data}

Website SEO optimization means that relevant measures are taken in website design to make key words related to the website rank among the top so as to increase page view of the website, realize enterprise brand promotion and increase website sales volume. For example, Amazon website belongs to America. In terms of overall sales, sales volume from instation recommendation system accounts for over 35\%.During website operation, customers visiting the website are tracked and their access behaviors are analyzed systematically. A recommendation model is established through relevant data, which can analyze and present favors of customers and demands of product functions comprehensively and show relevant internal products of enterprises on the web page. It is required to fully apply recommendation module in the process. Customers' attention can be attracted and they can be guided for commodity purchasing during web browsing through analysis on customer demands and favor.

In the process of website SEO optimization, big data is the basis for realizing such function. Reasonable data acquisition can guarantee optimized operation of website. Third-party big data platform should be fully applied in data analysis so as to specify optimization contents finally such as website picture, code and label and meanwhile improve website layout ${ }^{[2]}$.Page function design and layout can be mastered comprehensively in the process of full application of big data AB test. The influence of subjective factors will decrease obviously in the process. Meanwhile, data about user click can be obtained and users' tendency can be specified in the process of full application of big data. Under the background of reasonable application of parameters such as Baidu index, a lot of data basis can be provided for website SEO optimization.

In the process of website optimization, big data has the function of providing direction and can realize comprehensive website optimization from multiple perspectives and provide users with more personalized products and services of higher quality in the process of website management.

\section{Member marketing based on big data}

In traditional business process of enterprises, they often integrate the data of users purchasing their products and group all users through differential analysis so as to implement customer relation management and realize marketing interaction with customers. However, those making comments on enterprise commodities and services on the website include not only customers that have purchased commodities, but also some potential customers. Users' trade information and hobbies and interests are reflected on the website ${ }^{[3]}$. In the operational process, e-commerce enterprises must have comprehensive statistics of various behavior data of potential customers above. Such data may even exceed the information of users that have purchased commodities. Comprehensive integration of and in-depth analysis on such data can lay a good foundation for future establishment of more scientific and reasonable marketing strategies by enterprises. 
Such potential customer resources were completely neglected by e-commerce enterprises before the application of big data analysis. Enterprises could not analyze demands of potential customers and their opinions on enterprise services comprehensively and interactivity was seriously lacking in customer resource management. In the process of full application of big data analysis, defects in traditional customer resource management have been made up for and visitor relation management has replaced traditional customer relation management. Users purchasing commodities successfully will become members. Management has been strengthened in various links such as Add to Cart, Registration, Payment and Consumption, thus greatly improving member marketing level and making important contributions to the realization of sustainable development, the exploitation of customer resources and the improvement of product and service quality by e-commerce enterprises.

\section{Media advertisement based on big data}

Newspaper, television, magazine and broadcast etc. are main types of traditional media. Under the background of wide application of internet, mobile internet and PC internet have played a more and more important role in information transmission. New information transmission media have expanded the scope of advertisement marketing broadcast. Under the times background of big data, dynamic, personalized and accurate features become main features of advertisement marketing activities. In the operational process, e-commerce enterprises should conduct in-depth analysis on user data collected and outline features of target consumer group pertinently. They can conduct comprehensive analysis on consumer behavior data, tendency degree data and social content analysis data so as to master personalized demands of consumers, made dynamic advertisements pertinently, guarantee the compliance of advertisement contents with social relationship, interests and hobbies of target consumers and improve the attraction of advertisement contents. Meanwhile, to improve accuracy in the process of delivering advertisement contents, enterprises can also specify media channel and delivery time reasonably based on media preference of consumers. Finally, tracking evaluation of advertisement effect can be realized in the process of full application of feedback information and comments on social media platform. To improve functions and role of media advertisement with big data, e-commerce enterprises should conduct the following in the operational process:

First, enterprises should establish a special big data marketing plan and framework based on their own practical development. All employees should have strong consciousness of big data marketing so as to improve big data technical storage ability of enterprises on the whole. Second, it is required to strengthen internal big data marketing talent cultivation of enterprises and impel them to master complete theoretical knowledge and apply big data technology reasonably.

\section{Promoting significance of big data analysis for e-commerce marketing}

\section{Facilitate the improvement of information security service level}

With the rapid development of market economy in recent years, enterprises should face an environment with fiercer market competition in the business process. To improve comprehensive competitiveness under such circumstances, enterprises must master mass data resources and improve product and service quality pertinently through data mining and analysis so as to hold advantages in market competition. Security is vital in the process of application of mass data. Under such circumstances, e-commerce enterprises must avoid data loss through safety protection measures ${ }^{[4]}$.In fact, network vulnerability exists objectively. While carrying out influencing work with big data analysis, e-commerce enterprises can improve information security greatly and analyze and save data and information pertinently. This has great significance for improving comprehensive competitiveness of enterprises. 


\section{Facilitate marketing mode innovation}

With the improvement of living quality of people, there are higher and higher requirements for the quality of relevant products and services. Under such circumstances, e-commerce enterprises can fully master demands of target consumers through big data analysis, establish marketing strategies pertinently with accurate data provided by big data technology so as to promote the improvement of production efficiency and the realization of accurate marketing. Enterprises can establish a brand-new marketing mode on this basis, thus coping with market competition more flexibly and giving consumers experience and services of higher quality.

\section{Facilitate the improvement of ability of e-commerce enterprises to cope with emergency}

Data collection and analysis can be conducted efficiently under the times background of big data. Therefore, employees of e-commerce enterprises must have strong ability of cope with emergency so as to adjust marketing strategies appropriately and timely according to the result of big data analysis, provide high-quality services for consumers constantly and improve marketing level of enterprises. Effective application of big data analysis puts forward higher requirements for marketing personnel of e-commerce enterprises. Under such circumstances, enterprises shall strengthen the training of marketing personnel on knowledge such as computer capacity and marketing so as to realize sustainable development.

\section{Facilitate the realization of differentiated competition}

Faced with fierce market competition environment at home and abroad, e-commerce enterprises have constantly innovated their business and sales mode in the operational process so as to realize sustainable development. It is an impetus for enterprises to create more economic benefits. For example, enterprise changes and innovation can be seen everyday in the operational process of Alibaba Group, such as updating of Alipay and Taobao. Comprehensive competitiveness of enterprises has been improved. However, the importance of big data analysis can not be neglected in the process. Enterprise innovation has close relation with the result of big data analysis. Accurate analysis can prompt enterprises to realize self-adjustment effectively and, plus strong innovative competition, impel enterprises to realize differentiated competition so as to create more economic benefits.

\section{Facilitate the improvement of user experience}

Behavioral habits and personal preference of consumers can be integrated comprehensively on the basis of big data analysis. Goods and service transformation of e-commerce enterprises on this basis can improve customer satisfaction effectively and give consumers unique experience. Therefore, e-commerce enterprises must conduct market division, prevent market loss, endeavor to attract brand-new visitors and lay a good foundation for creating more economic benefits constantly based on consumer demands in the operational process.

\section{Conclusion}

In conclusion, big data analysis has emerged and been widely applied under the background of constant progress of information technology. Functions and importance of big data analysis have gradually been prominent in recent years. E-commerce enterprises have created more economic benefits through reasonable use of big data analysis. To avoid the loss of regular customers and attract more new customers effectively, e-commerce enterprises must be clear about the promoting significance of big data analysis for e-commerce marketing. Only in this way can they fully use big data analysis, based on their reality so as to improve their own comprehensive competitiveness constantly and realize sustainable development. 


\section{References}

[1] Wu Qingyan. Study on E-commerce Marketing Strategies for Agricultural Products under the Background of "Internet +" - Take Marketing of Hainan Mango for Example, Chinese Market, 2016(27):22-24.

[2] Zhu Yan, Han Xiaoning. Study on E-commerce Marketing Mode for Agricultural Products under the Thinking of "Internet +" - Take Marketing of Large Cherry in Yantai in 2015 for Example. Horizon of Science and Technology, 2016(3):24-25.

[3] Deng Liming, Huang Yue, Jia Xinge et al. Study on Cognition and Identification of the Public about E-commerce Marketing of Aquatic Products, Education and Teaching Forum, 2016(29):126-127.

[4] Wang Xinchen. Application of Data Mining Technology in E-commerce Marketing Development under the Background of Big Data - Take an E-business Enterprise for Example, Productivity Research, 2017(4):64-67.

[5] Zhang Lijia. SWOT Analysis on E-commerce Marketing of Agricultural Products *- Take Mandarin Orange in Huangyan for Example, Logistics Engineering and Management, 2016,38(12):131-133. 